\title{
ANÁLISE COMPARATIVA DO EMPREGO DE CONCRETO BETUMINOSO COM ADITIVO SURFACTANTE E PRÉ-MISTURADO A FRIO EM SERVIÇOS DE MANUTENÇÃO RODOVIÁRIA
}

\section{ARTIGO ORIGINAL}

TELES, Jeferson Barros ${ }^{1}$

ASCENSO, Thalia Alves ${ }^{2}$

FLORENÇO, Silvio de Souza ${ }^{3}$

FONSECA, Luiz Felipe da Silva da ${ }^{4}$

TELES, Jeferson Barros. Et al. Análise comparativa do emprego de concreto betuminoso com aditivo surfactante e pré-misturado a frio em serviços de manutenção rodoviária. Revista Científica Multidisciplinar Núcleo do Conhecimento. Ano 05, Ed. 11, Vol. 02, pp. 45-62. Novembro de 2020. ISSN: 2448-0959, Link de acesso: https://www.nucleodoconhecimento.com.br/engenharia-civil/emprego-deconcreto

\section{RESUMO}

O presente estudo trata-se de uma análise comparativa do uso de concretos betuminosos: usinado a quente com aditivos surfactantes e pré-misturados a frio em operações de reparo localizado em pavimentos flexíveis, como tapa buraco e remendo. Para poder entender o processo é necessário começarmos pela compressão ao tema de pavimentos especialmente ao flexível. Visto que, por ser um dos mais frágeis, tende com maior facilidade ser exposto às deformações precisando

\footnotetext{
${ }^{1}$ Estudante de Engenharia Civil.

2 Estudante de Engenharia Civil.

${ }^{3}$ Estudante de Engenharia Civil.

${ }^{4}$ Orientador. Mestrado em Engenharia Civil pela UFRJ.
} 
de reparações e ações preventivas com mais frequência. $O$ revestimento asfáltico mais comum na pavimentação flexível é o concreto betuminoso usinado a quente (CBUQ) que na execução de tapa-buracos é comumente utilizado com aditivo surfactante mudando sua trabalhabilidade permitindo aplicá-lo a freio. Esse produto tem grande durabilidade e resistência, podendo ser usado na reparação asfáltica em períodos de chuvas e o próprio tráfego contribui na compactação do produto. Outro concreto bastante utilizado nessa pavimentação é o pré-misturado a frio de baixo custo e sua produção tem um modo mais simples quando comparado ao CBUQ. A pesquisa será feita através de estudos de referências bibliográficas de autores e órgãos que abordam sobre o tema como José Tadeu Balbo, Cinthya Batista de Salles, DNIT e Liedi Légi Bariani Bernucci. O objetivo do estudo é analisar ambos os concretos betuminosos em suas características como fabricação, composição, aplicação, durabilidade e custo a fim de compreender qual garante melhor resultado em função da finalidade de aplicação.

Palavras-chave: Pavimentação flexível, pré-misturado a frio, usinado a quente, aditivos surfactantes, tapa-buracos.

\section{INTRODUÇÃO}

Quando se trata de pavimentação asfáltica é possível abordar várias opções, sendo uma área vasta de tecnologia e conhecimento, visto que varia de acordo a necessidade do cenário, especialmente o brasileiro. Com o aumento do tráfego verse a necessidade de construções rodoviárias evitando acidentes riscos de acidentes, além de garantir a segurança dos condutores e passageiros.

Com o grande fluxo de automóveis, os pavimentos acabam sofrendo deformações, precisando de reparos. Com isso, é preciso analisar alguns fatores na construção dos asfaltos para ter durabilidade. Do mesmo modo, deve-se escolher o melhor produto para reparar os defeitos existentes.

Contudo, o presente estudo deu-se pela necessidade investigativa do uso de usinados a quente (CBUQ), com aditivo surfactante, ou também como é mais conhecido o 
CBUQ aplicado a frio, e o Pré-misturado a frio em operações de tapa-buraco. Duas vertentes de aplicações asfálticas que viabilizam a segurança e qualidade dos pavimentos.

Inicialmente, o estudo abordará sobre o que se trata a pavimentação flexível, uma modalidade de pavimento mais fabricado pelas construtoras de pavimentos rodoviários. Sua composição é feita por misturas de ligantes asfálticos com betumes e agregados, sendo construído em camadas como revestimento, base, sub-base e reforço do subleito. No pavimento flexível, as cargas dos veículos são distribuídas em todas as camadas. Também é a pavimentação que mais sofre deformação elástica, necessitando de manutenções.

Um dos materiais utilizados na construção e reparos da pavimentação asfáltica flexível é o Concreto betuminoso usinado a quente (CBUQ). Sua produção é realizada em usinas a quente, podendo ser aplicado a frio onde acrescenta-se aditivo surfactante.

Outra mistura asfáltica destinada à reparação do pavimento flexível é o Concreto Betuminoso Pré-misturado a frio, sendo um produto mais prático e com menor custo para a fabricação, porém tem pouca resistência, não sendo indicada sua aplicação em rodovias com um alto tráfego.

O objetivo do trabalho é analisar as duas misturas asfálticas no processo de fabricação, composição, aplicação, custos e durabilidade, a fim de saber qual tem uma qualidade melhor para ser aplicado na reparação asfáltica. É importante saber que esses revestimentos são diferentes, mas são usados com uma mesma finalidade na construção e reparação de pavimentos flexíveis.

\section{FUNDAMENTAÇÃO TEÓRICA}

A pavimentação asfáltica é uma obra civil que advém da necessidade de melhoria na locomoção de veículos na área urbana, pois chuvas trazem grandes danos às rodovias e estradas, causando deslizamentos e enchentes. Para Balbo (2007, p. 13), 
Sem estradas adequadas não apenas continuaremos a ser uma região fora do espectro das nações desenvolvidas, como também continuaremos a ser um País que não oferece acesso adequado de bens para sua população. Não nos ufanemos, portanto, de nossa infraestrutura rodoviária, ainda bastante arcaica, que demonstra baixa tecnologia a serviço, reflexo de nosso atraso como sociedade moderna. (BALBO, 2007, p. 13)

O especialista ainda aborda que as funções dos pavimentos são oferecer uma superfície mais regular para garantir comodidade aos veículos e superfície aderente, onde oferta maior segurança aos motoristas e passageiros. (BALBO, 2007).

O projeto de pavimentação asfáltica é realizado pelo profissional de engenharia civil, onde sua competência é atuar nas cidades, rodovias, portos e aeroportos. Esse deve conhecer os tipos de pavimentações; projeto de drenagem e tráfego; tecnologia; estrutura, manutenção, gerência e mecânica dos pavimentos; materiais a serem utilizados na construção do asfalto e geotecnia. (DOOM, 2016).

A atuação do engenheiro é essencial na avaliação dos materiais, condições do local, do solo e geotecnia, bem como na implantação, pois é atribuição do profissional supervisionar na obra e na manutenção de áreas danificadas.

Diversas vezes são feitas contagens de tráfego e pesquisa de ocupação de carga, não sendo feita pesagem. A análise destes dados inclui determinação dos fluxogramas de tráfego na rodovia e nas principais interseções, a projeção de crescimento do tráfego futuro, os fatores de veículo e Número "N".

O número "N", é necessário ao dimensionamento das soluções de restauração do pavimento existente e de pavimentos novos no projeto em questão, é definido pelo número de repetições do eixo-padrão, durante o período de vida útil do projeto, que teria o mesmo efeito que o tráfego previsto sobre a estrutura do pavimento (FONSECA, 2013)

Sobre a estrutura, para ter resistência às cargas dos veículos e ao clima, o pavimento é feito em diversas camadas, sendo formadas por meio de um conjunto em que sofrerá tensões e deslocamentos, sendo assim, como toda estrutura de uma construção civil 
em que os pesos são divididos de forma que seja compatível com a resistência de cada camada do pavimento asfáltico. (MOTTA, 1995).

$\mathrm{Na}$ pavimentação asfáltica, sua estrutura é formada por camadas que serão construídas após a realização da terraplenagem sobre o subleito, variando conforme solicitado ao tráfego daquela região. As camadas serão feitas por cima do subleito que irá receber os impactos absorvidos pela pavimentação. Acima dessa camada será realizada a construção do reforço de subleito, caso for preciso, a sub-base em cima do reforço de subleito, a base e no final o revestimento.

Em relação às camadas para a realização da pavimentação, elas se encontram geralmente em cinco, sendo o revestimento a camada principal que é designada a resistir aos impactos causados pelo tráfego e distribuir para as camadas seguintes. (MEDINA, 1997). É a camada que irá receber as ações diretas da locomoção dos veículos. O revestimento deve ser feito com uma boa qualidade para uma maior durabilidade e conforto aos condutores de automóveis e um bom rolamento da pista. Por sua vez, essa é a que deve ser construída com materiais de maior custo. Sua qualidade está ligada a qualidade do subleito, sendo assim, não há necessidade de grandes espessuras do revestimento e de outras camadas, no caso do subleito estiver com uma ótima qualidade.

Há três tipos de pavimentações: rígida, semirrígida e flexível. No Brasil, as maiorias das empresas atuam na construção do pavimento flexível.

O pavimento flexível é uma estrutura feita em camadas com intuito na distribuição e resistência dos esforços do tráfego, impermeabilização das camadas mais frágeis do asfalto e oportunizar mais qualidade de rolamento a segurança e comodidade do ser humano. Segundo o Manual de Pavimentação do Departamento Nacional de Infraestrutura de Transportes - DNIT (2006, p. 95),

Aquele em que todas as camadas sofrem deformação elástica significativa sob o carregamento aplicado e, portanto, a carga se distribui em parcelas aproximadamente equivalentes entre as camadas. (DNIT, 2006) 
O pavimento flexível é feito pela camada de revestimento sobre outras camadas construídas por misturas, solos e materiais granulares.

Figura 1 - Deformação Elástica de Carga no Pavimento Flexível

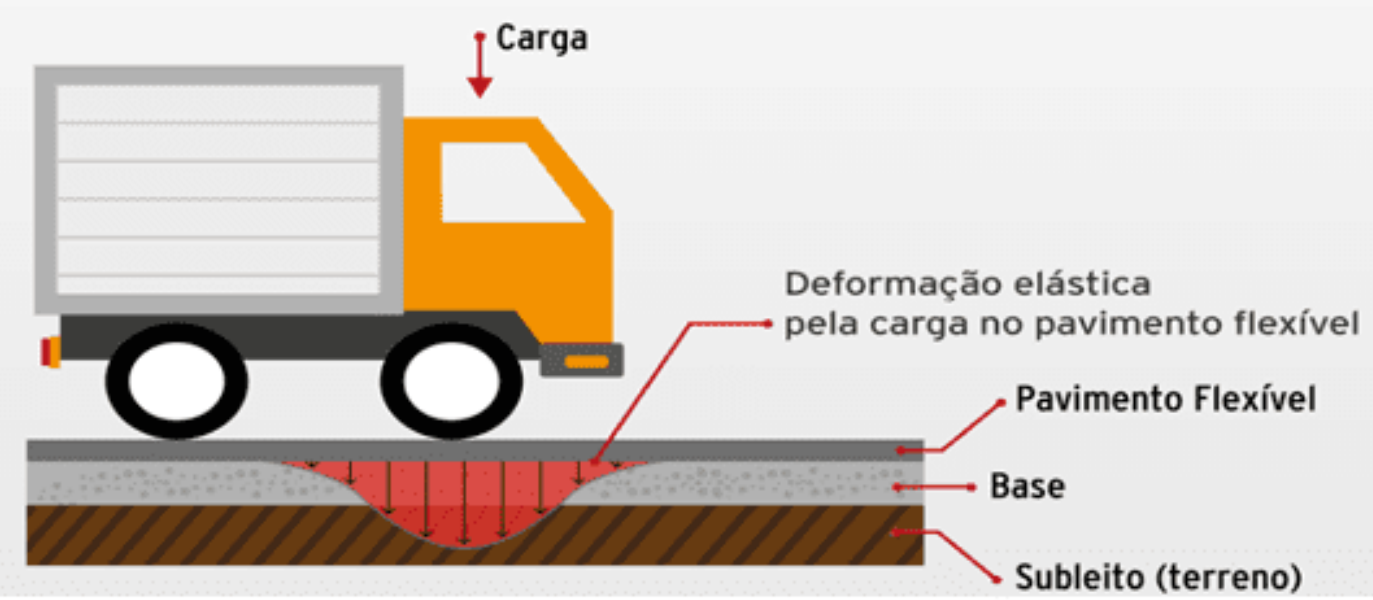

Fonte: CNT (2017).

Essa pavimentação é feita por mistura de ligante asfáltico com agregados e betumes, o qual possui uma elevada viscosidade, sendo uma mistura líquida com procedência artificial ou natural. O revestimento é colocado em cima das camadas de base, subbase e do reforço subleito, onde pode há vários materiais como camada granular.

\subsection{REVESTIMENTO ASFÁlTICO DE CONCRETO BETUMINOSO USINADO A QUENTE (CBUQ), COM ADITIVO SURFACTANTE}

O Concreto Betuminoso Usinado a Quente (CBUQ) é um revestimento flexível e segundo Senço (2001) trata-se de um produto que resulta de misturas a quente de Cimento Asfáltico de Petróleo (CAP) e agregados minerais. Porém, sua aplicação poderá ser a frio quando são utilizados aditivos químicos, onde permite a aplicação a frio e estocagem do CBUQ. Também, contribui para redução das temperaturas de usinagem, bem como as temperaturas dos agregados.

São diversos aditivos que podem ser aplicados nas misturas asfálticas mornas e para Cheng et al. (2011) para escolher qual deve ser utilizado, depende da análise de 
questões como a temperatura adequada para 0 projeto, pois as reduções das temperaturas variam conforme $o$ aditivo que foi usado.

Um dos produtos químicos utilizado é o aditivo surfactante e conforme o pensamento de Mota (2011), esse serve para diminuir a temperatura na hora da produzir e compactar as misturas utilizadas na produção do asfalto sem reduzir a qualidade do CBUQ convencional. Sua aplicação poderá ser feita de forma direta no processo de mistura ou ao ligante.

Para Motta (2011, pg. 27) "esse aditivo não faz alterações na consistência do asfalto, medida no ensaio de penetração, ponto de viscosidade e de amolecimento e a redução da temperatura que segue a ordem de 30 a $40^{\circ} \mathrm{C}$.

A aplicação de aditivos surfactantes no $\mathrm{CBUQ}$ ainda reduz a viscosidade do ligante asfáltico, o que proporciona cobrir de modo completo os agregados pétreos sem utilizar temperaturas elevadas no processo de usinagem. Com a diminuição da viscosidade do ligante, o aditivo pode agir como facilitador durante a compactação. (KRISTJANSDOTTIR, 2006).

Além de oferecer maior durabilidade e desempenho que as misturas convencionais, usando baixa temperatura, o aditivo surfactante contribui para o meio ambiente, diminuindo o envelhecimento do ligante asfáltico, reduzindo consumo de combustíveis e a compactação de temperaturas que são aplicadas nas misturas tradicionais. (D'ANGELO et al., 2008; VAITKUS et al., 2016).

Em se tratando da produção, assemelha-se com o CBUQ convencional, em que as usinas de asfaltos misturam a quente o CAP e os agregados pétreos. No decorrer da fabricação, é aplicado o aditivo o qual permite o uso em um longo tempo, mesmo depois de encontrar-se frio. Quando é retirado da usina, é realizada a estocagem e ensacamento para ser comercializado, bem como pode ser ofertado a granel. Poderá ser estocado e ensacado no prazo de até 12 meses, pois o aditivo surfactante cria uma película em cima da massa, assim protege o asfalto do endurecimento e da compactação de forma indesejada. 
Outras vantagens são encontradas na facilidade de transportar e pela facilidade em utilizar, pois é só limpar a região a ser aplicado, retirar o produto do saco, espalhar e fazer a compactação, devido não ser emulsionado.

Por não ser emulsionado, não é necessário realizar a pintura da ligação e a imprimação. As seguintes etapas não precisam ser realizadas como na massa asfáltica convencional devido o aditivo já oportunizar uma ótima adesão do revestimento sobre as camadas inferiores, sem grudar, por exemplo, solas de calçados e pneus de automóveis. (NOVO ASFALTO, 2018).

Em questão da compactação, pode ser realizada pelos próprios pneus de carros e máquinas de rolos lisos e permite ser aplicado em período chuvoso, pois é preparado para ser compactado e aplicado em temperatura ambiente.

A figura mostra a aplicação do CBUQ aplicado a frio com acabadora.

Figura 2- Aplicação do CBUQ a frio com acabadora

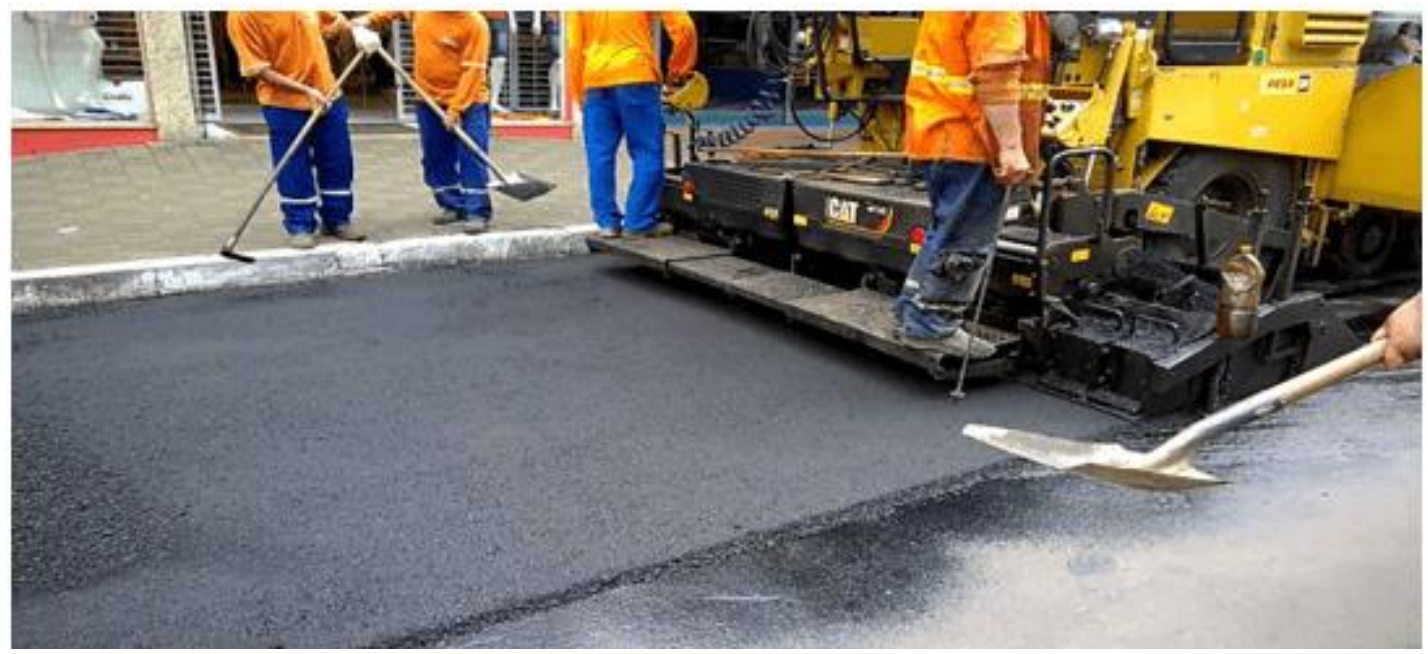

Fonte: Carlos Barbosa (2017)

\subsection{REVESTIMENTO ASFÁLTICO PRÉ MISTURADO A FRIO (PMF)}

$\mathrm{O}$ asfalto Pré-misturado a frio consiste em uma mistura preparada em uma usina adequada, sendo esse destinado na construção de revestimento asfáltico, bem como 
em operações de tapa-buracos. Geralmente sua composição é de agregados graúdos, como a brita, e miúdos (areia ou pó de pedra) e ligantes - emulsão asfáltica. (DNIT 153/2010-ES).

O PMF é espalhado e compactado na pista sob uma temperatura ambiente, do mesmo modo em que ocorre durante o processo na usina.

Seu processo de fabricação nas usinas é simples, em que dispensa o acaloramento dos ligamentos e dos agregados. As usinas são móveis ou estacionárias, onde fazem a mesclagem do agregado com a emulsão asfáltica. As estacionárias são destinadas no processo de misturar, britas, cimentos, solos, entre outros. Algumas possuem silos individuais onde as portas são reguláveis para os agregados em que esses são descarregados em uma correia transportadora, sendo levada diretamente ao misturador e assim, é injetada a emulsão asfáltica na porção que é estabelecida. Já as usinas móveis preparam o PMF em um único maquinário, conforme a figura 2 (Chassi), produzindo o produto em um curto tempo. (BERNUCCI, 2008).

Figura 3 - Usina Móvel para fabricação do PMF

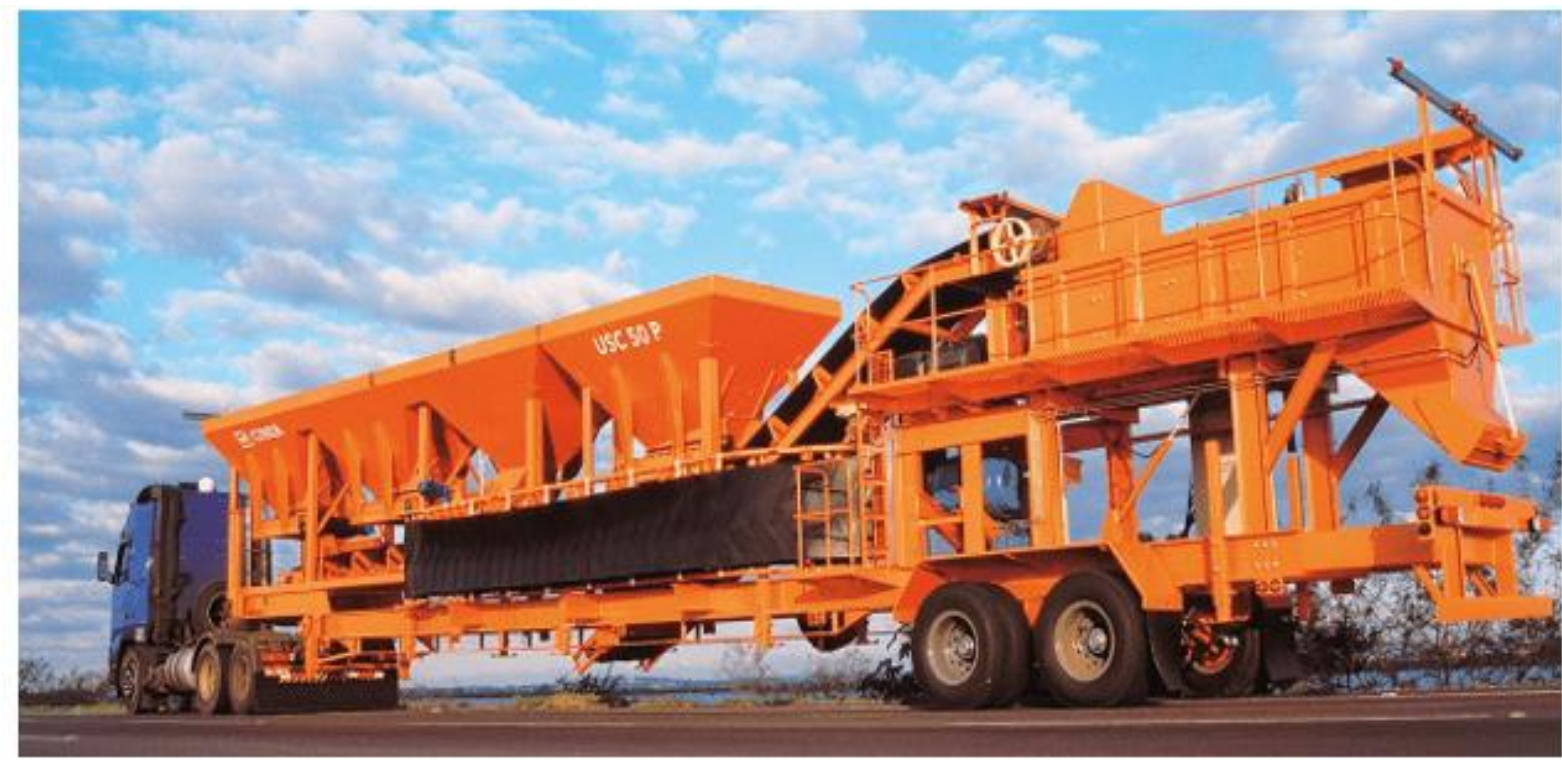

Fonte: Novo Asfalto (2018) 
Abeda (2010) afirma que as prefeituras vêm adotando o uso de PMF na pavimentação das ruas devido o baixo custo da utilização do material e por não exigir uma grande equipe técnica, ainda pela facilidade para obtenção da massa asfáltica e pela aplicação na pista com equipamentos como motoniveladoras e vibro acabadoras.

Bernucci (2008) menciona as vantagens do uso do PMF, sendo: na utilização de equipamentos para aplicação serem mais simples; aplicabilidade em temperatura ambiente; a mobilidade do produto, contribuindo na redução de custos da logística; aplicação fácil e rápida; poderá fazer o uso de agregados úmidos sem a necessidade de aquecimento do material; permite estocar na dosagem asfáltica; redução de exalação tóxica, assim preservando o meio ambiente e a saúde.

\subsection{O USO DE MATERIAIS BETUMINOSOS CBUQ COM ADITIVO SURFACTANTE E PMF EM OPERAÇÕES TAPA-BURACOS}

O pavimento flexível passa por deformações elásticas sendo necessária à sua reparação. Desse modo ocorrem as operações tapa-buraco. Para a reparação dessa pavimentação asfáltica, são comuns o uso de concretos betuminosos a quente aplicados a frio e o pré-misturado a frio. Ambos oferecem praticidade na hora de fazer os reparos asfálticos.

O CBUQ com aditivo surfactante permite fornecer, estocar e transportar em pequenas quantidades. Ainda, poderá ser aplicado em dias de chuva e até em buracos cheios de água. Sua fórmula ainda contribui no momento de compactação, onde não são necessários maquinários pesados e mão de obras robustas, com isso, ajuda na redução de custos por utilizar equipamentos simples e poucos colaboradores para realização do trabalho. Outra vantagem é que não tem tempo de espera para usar a rodovia em que foi reparada com o CBUQ aplicado a frio, pois no mesmo momento a pista poderá ser utilizada.

Já em questão do processo de fabricação e custos, o PMF possui maior vantagem. Porém, seu uso deve ser em pavimentações com um baixo tráfego, por não suportar cargas fortes. Não poderá ser aplicado quando estiver chovendo e nem se o buraco 
estiver com água. Só poderá ser estocado em curto prazo. A figuras a seguir, mostram antes e depois da aplicação do PMF.

Figura 4 - Aplicação do PMF

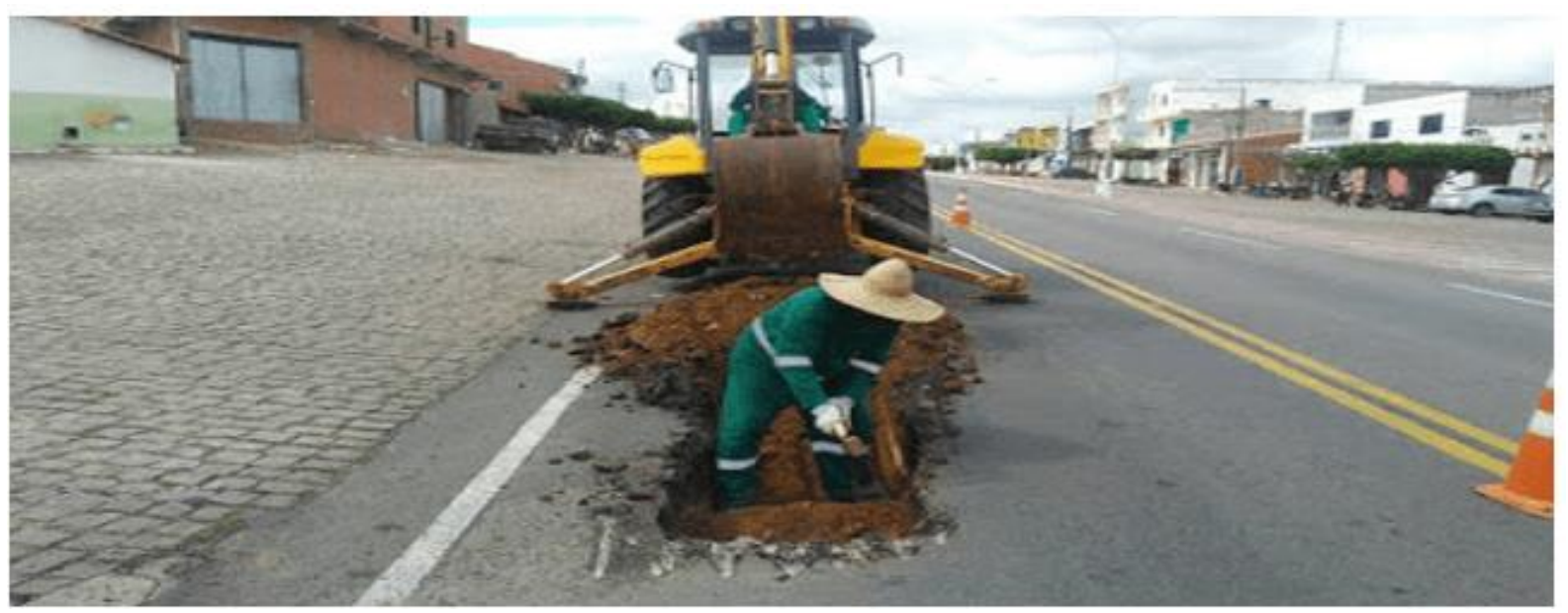

Fonte: Aelson Fotos (2019)

Figura 5 - Após aplicação do PMF

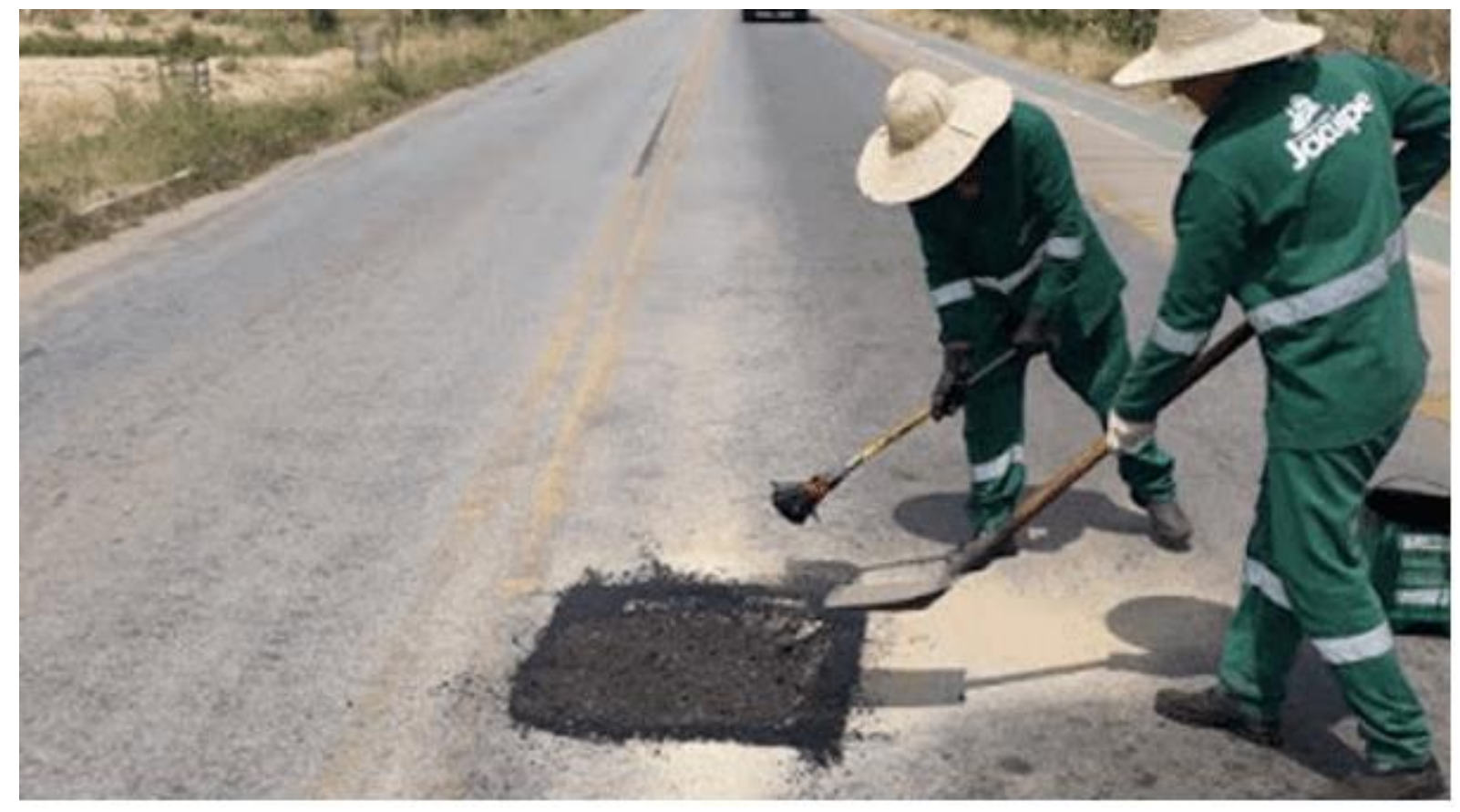

Fonte: Aelson Fotos (2019) 


\section{MATERIAIS E MÉTODOS}

Na pesquisa em pauta a que se refere o estudo, foi utilizado o método de pesquisa bibliográfica e documental, com estudo descritivo feito a partir de materiais como livros e dissertações que abordam sobre o uso de concretos betuminosos usinado a quente com aditivo surfactante e o pré-misturado a frio para reparar os danos nos pavimentos flexíveis.

A reflexão baseia-se na necessidade de compreender o processo de recuperação dos pavimentos asfálticos flexíveis. Um recorrente problema enfrentado no cenário brasileiro principalmente em épocas de chuva são os buracos que se encontram nas rodovias. As reclamações são diárias e muitos são questionamentos sobre o porquê as reparações das pistas tem pouca durabilidade.

A partir desse ponto, é importante analisar sobre quais materiais são utilizados na construção dos pavimentos flexíveis, sendo os mais comuns o concreto betuminoso a quente e o pré-misturado a frio. As seguintes misturas também são bastante usadas nas operações tapa-buracos, porém o $\mathrm{CBUQ}$ é preparado a morno e aplicado a frio com aplicação de aditivo surfactante para diminuir a temperatura.

Para uma melhor escolha de qual mistura asfáltica utilizar na reparação dos asfaltos é necessário fazer uma análise dos diversos materiais destinados para essa finalidade. Porem pode ocorrer mudanças, tendo em vista as verbas que são atribuídas aos municípios, estados e país, assim o fator que é mais julgado é o menor custo, o que pode refletir na qualidade.

O CBUQ aplicado a frio e o PMF são produtos diferentes, mas tem algumas similaridades. Mas antes de aplicá-los é essencial que tenha o conhecimento de qual é adequado para determinada região, com isso, o papel do engenheiro civil é fundamental para o estudo do local e saber qual produto a ser usado e também na fiscalização da execução dos reparos. Essa reparação deve oferecer maior comodidade aos que estão no veículo e segurança, pois uma boa pavimentação evita riscos de acidentes e danos aos carros e melhor rolamento. 
A partir disso, a pesquisa em pauta buscou extrair informações através relatos de estudiosos sobre o tema apontando, sobre o tipo de cada concreto betuminoso, o seu processo de fabricação, os maquinários e equipamentos utilizados na composição, durabilidade e custos.

\section{RESULTADOS E DISCUSSÃO}

O concreto betuminoso usinado a quente com aditivo surfactante e o Pré-misturado a frio são materiais de revestimentos asfálticos diferentes, porém podem ser utilizados na mesma função em operações tapa-buracos nas pavimentações flexíveis.

A partir disso, deu-se a comparação dos dois produtos com intuito de analisar qual é o mais benéfico para o reparo nas ruas e rodovias. em relação à composição, os dois possuem agregados minerais, como pó-de-pedras, britas e filler calcário (material feito através da moagem fina do calcário) e ligante asfáltico que faz a junção. No PMF, o ligante asfáltico é misturado na água, ocorrendo à emulsão asfáltica catiônica, permitindo maior adesividade com os agregados. Os agregados podem ser misturados úmidos. (DNIT 153/2010-ES).

Já no CBUQ com aditivo surfactante, o ligante precisa ser aquecido para ocorrer a mistura dos agregados e seu produto é semissólido feito em temperatura ambiente. Esse é uma mistura, em geral, entre os agregados minerais (95\%) com o Cimento Asfáltico de Petróleo (5\%). Os agregados têm como objetivo oferecer a resistência e estabilidade ao asfalto e o CAP a flexibilidade e durabilidade do material. (NOVO ASFALTO, 2018).

Em questão de fabricação, segundo Bernucci (2008), o PMF é feito em usinas de prémisturado a frio, sendo essas mais simples e em temperatura ambiente. Não precisa de sistemas que realizam a secagem do produto. Enquanto o CBUQ é fabricado em uma usina de asfalto a quente convencional e para ser aplicada a frio, são acrescentados aditivos surfactantes. 
O CBUQ com aditivo surfactante, poderá ser aplicado até em tempos chuvosos e não é necessário um tempo de espera para poder utilizar a pista em que foi reparada com o material, pois o próprio tráfego contribui para a compactação. O PMF já é um produto mais frágil e exige um período de cura para que mantenha a adesivagem do ligante.

Conforme Novo Asfalto, 2018, ao reparar um asfalto com esse material, é de fundamental importância que não ocorra abertura ao tráfego no prazo de 12 horas e nem que haja aplicação em dias chuvosos e quando estiver no período de cura, sendo o de evaporação da água da emulsão e da mistura.

Apesar de serem produtos diferentes, podem ser usados na mesma finalidade, sendo essencial fazer uma análise comparativa, a fim de saber questões como qualidade e custo.

Inicialmente, observa-se o processo de fabricação e os materiais em que compõem esses concretos betuminosos. O CBUQ aplicado a frio passa pelo mesmo processo de criação do convencional, logo se diferenciam durante a adição de aditivos surfactantes que diminui a temperatura para ser usado a frio e o PMF é feito a frio, sem o uso de métodos de secagem dos agregados e o ligante asfáltico é misturado na água. (NOVO ASFALTO, 2018).

Em se tratando na aplicabilidade dos produtos para tapar buracos, ambos têm sua aplicação a frio logo não se diferenciam nesse aspecto, podendo ser ensacados e estocados, entretanto o PMF é mais susceptível as intempéries, por exemplo, não deve ser aplicado durante chuva e seu prazo de estocagem é muito mais curto quando comparado ao CBUQ com aditivo surfactante, não devendo ultrapassar de 5 dias estocado, além de não ser recomendada a liberação do tráfego imediatamente após a execução do tapa buraco com emprego de PMF. Assim o CBUQ aplicado a frio é mais vantajoso devido o período de estocar ser mais longo, podendo ser aplicado em qualquer clima e após ser usada para tapar buraco, a locomoção de veículos pode ser liberado, ajudando na compactação. 
O PMF possui o melhor custo, mas não permite ser aplicado em regiões onde tem alto tráfego, podendo ter duração curta, assim o CBUQ com aditivo surfactante aplicado a frio a frio por ter um grande período de durabilidade e grande resistência em rodovias com alto índice de movimentação de veículos, o preço mais alto compensa, satisfazendo a necessidade de manter um bom asfalto em um longo tempo. No quadro 1 , será apresentada uma comparação das características de ambos os concretos betuminosos.

Quadro 1- Comparativo das características dos Concretos Betuminosos CBUQ a frio e o PMF

\begin{tabular}{|c|c|c|c|}
\hline Caracteristica & $\begin{array}{l}\text { Asfalto } \\
\text { Frio }\end{array}$ & CBUQ & PMF \\
\hline $\begin{array}{l}\text { Usinado a } \\
\text { quente }\end{array}$ & $\sin$ & $\operatorname{sim}$ & não \\
\hline $\begin{array}{l}\text { Usinado a frio } \\
\text { (emulsionado) }\end{array}$ & nāo & nāo & $\sin$ \\
\hline Estocável & 2 anos & nāo & 5 dias \\
\hline $\begin{array}{r}\text { Aplicação na } \\
\text { chuva }\end{array}$ & sim & nāo & nāo \\
\hline $\begin{array}{r}\text { Liberação do } \\
\text { tráfego }\end{array}$ & Imediata & $5 \mathrm{~h}$ & $12 \mathrm{~h}$ \\
\hline Resistência & Alta & Alta & Baixa \\
\hline Vida útil & Alta & Media & Baixa \\
\hline Preço & Alto & Médio & Baixo \\
\hline $\begin{array}{l}\text { Custo a medio } \\
\text { e longo prazo }\end{array}$ & Baixo & Médio & Alto \\
\hline
\end{tabular}

Fonte: Novo Asfalto (2018) 
Neste sentido, após os estudos realizados, conclui-se que o CBUQ com aditivo surfactante, quando comparado ao PMF na execução de serviços de tapa-buraco, apresenta um melhor comportamento pelo fato de ser mais resistente ao tráfego, maior durabilidade, não precisa interditar a pista após a aplicação do produto, pois os próprios automóveis fazem a compactação e pode reparar o asfalto nos climas chuvosos. Apesar de seu custo ser maior, acaba não sendo desvantagem por ser um material de vida longa e resistente e por poder fazer a liberação do tráfego com maior agilidade.

Portanto, compreende-se que entre os dois concretos betuminosos para a reparação de rodovias que possuem buracos, a melhor escolha será o uso do CBUQ aplicado a frio, Uma vez que se apresenta mais resistente quando comparado ao PMF, de forma a acomodar maiores solicitações do tráfego, além de permitir sua aplicação em dias chuvosos, o que deve ser evitado quando utilizado o PMF. Outro aspecto positivo do CBUQ com aditivo surfactante é não necessitar de tempo de cura, podendo ser liberado ao tráfego imediatamente. Sua desvantagem ao PMF é em questão de custos na produção e dos materiais, sendo mais caro nesses aspectos.

\section{CONSIDERAÇÕES FINAIS}

Baseado nos estudos realizados para elaboração do presente artigo, investigando as várias formas de execução de reparos localizados em pavimentos flexíveis, foi possível concluir que as soluções mais empregadas são a execução com CBUQ convencional e PMF. Com o concreto betuminoso usinado a quente aplicado com aditivo surfactante, observa-se que para a garantia do que se espera ocorre uma aplicação de elementos químicos para que possa ser aplicado a frio.

Pesquisar sobre os pavimentos flexíveis e fazer esse parâmetro comparativo contribuíram para a ampliação da visão profissional do engenheiro civil, esse que realiza o projeto da construção da pavimentação asfáltica e deve analisar fatores antes do início da obra, durante na fiscalização e nas reparações. 
A análise ocorreu por volta da utilização do concreto usinado à quente aplicado a frio em operações tapa-buracos. Essa mistura asfáltica é produzida primeiramente como CBUQ convencional e após é usado aditivo surfactante para diminuição da temperatura. Com isso pode ser ensacado e estocado, contribuindo para melhor locomoção do produto até o local a ser usado, permitindo ficar assim em um longo prazo. Ainda pode ser aplicado durante chuvas ou com buracos com água. Quando aplicado ao pavimento, não precisa interditar a locomoção dos veículos, pois ajuda na compactação. O revestimento tem maior tempo de duração pelo fato de ser um material resistente.

Já o concreto pré-misturado a frio é um produto mais simples, com baixo custo, levando vantagem ao CBUQ. Mas, não pode ser usado quando estiver em período de chuva, quando é usado na reparação das rodovias, precisa ter um prazo para permitir a locomoção de veículos e por ter menos resistência, não pode ser utilizados em pavimentos onde possui um alto tráfego, pois sua duração pode ser apenas em meses.

Os dois se assemelham em sua composição, pois, contém agregados minerais, como pó-de-pedras, britas e filler calcário e por último o ligante asfáltico para a junção. Já no pré-misturado a frio, o ligante asfáltico é misturado na água ocorrendo o processo emulsão asfáltica catiônica, contribuindo com uma maior adesividade. Com o CBUQ é necessário um aquecimento para ocorrer a mistura dos agregados.

Portanto, com o estudo comparativo das seguintes misturas asfálticas utilizadas em operações de tapa-buracos, percebeu-se que em questão de qualidade o Concreto betuminoso usinado a quente aplicado a frio tem mais vantagens na aplicação do produto, por ser mais resistente, suportando o alto tráfego de veículos e por ter grande durabilidade, assim vale a pena o investimento alto para obter bons resultados e que sejam duradouros. 


\section{REFERÊNCIAS}

ABEDA - Associação Brasileira das Empresas Distribuidoras de Asfaltos. Manual Básico de Emulsões Asfáltica, Brasil 2001.

AELSON FOTOS. Mais de $\mathbf{1 3 0 0}$ toneladas de pré misturado a frio - pmf foram utilizados em todo território durante este ano pelo consórcio jacuípe, 2019. Disponível em: <http://www.aelsonfotosevideo.com.br/2019/10/mais-de-1300toneladas-de-pre-misturado.html>. Acesso em: 28 de maio de 2020.

BALBO, J. T. Pavimentação Asfáltica: materiais, projeto e restauração. São Paulo: Oficina de Textos (2007).

BARBOSA, Carlos. Aplicação CBUQ a frio com vibro acabadora (parte 2). Disponível em: <https://www.youtube.com/watch?v=g5ISsIAM70l>. Acesso em: 28 de maio de 2020.

BATISTA, Cinthya de Salles; AMANAJÁS, Renan Diego Lima da Silva. Uma análise sobre o novo conceito de massa asfáltica de concreto betuminoso usinado à quente com armazenamento a frio - CBUQ, Manaus, 2018.

BERNUCCI, L. B.; CERTTI, J. A.P.; SOARES, J. B. Pavimentação Asfáltica. Formação básica para engenheiros, Rio de Janeiro, 2008.

CHENG, D.; HICKS, R. G.; TEESDALE, T. Assessment of warm mix technologies for use with asphalt rubber paving applications. In: Transportation Research Board Annual Meeting, 2011. Washington D.C.

D'ANGELO, John; et al. Warm-Mix Asphalt: European Pratice. International Technology Scanning Program. Federal Highway Administration. Virginia, 2008.

DNIT (2016). NBR- XXX/2016 - ES - Pavimentação - Misturas asfálticas mornas com uso de surfactante. - Especificação de serviço. Associação Brasileira de Normas Técnicas. Brasília. 
DNIT (2016). NBR- 153/2010 - ES - Pavimentação asfáltica - pré misturado a frio com emulsão catiônica convencional. - Especificação de serviço. Associação Brasileira de Normas Técnicas. Rio de Janeiro.

DOOM, Fabio. BDE Explica: o que é pavimentação asfáltica?, 2016. Disponível em< https://engenharia360.com/bde-explica-o-que-e-pavimentacao-asfaltica/ >. Acesso em: 20 de maio de 2020.

FONSECA, L. F. S. Análise das soluções de pavimentação do programa crema $2^{\text {a }}$ etapa do departamento nacional de infraestrutura de transportes. UFRJ COPPE - M.Sc. 2013.

KRISTJANSDOTTIR, Olof. Warm mix asphalt for cold weather paving. Masters Dissertation. University of Washington. Seattle, 2006.

MEDINA, J., Mecânica dos Pavimentos, Editora UFRJ (1997).

MOTTA, L.M.G. (1995). Considerações a respeito de pavimentos e tráfegos em vias urbanas. In: REUNIÃO DE PAVIMENTAÇÃO URBANA, 6ª 1995, Santos. Anais. Santos, Associação Brasileira de Pavimentação, Santos. p 25-52.

MOTTA, R. S. Estudo de misturas asfálticas mornas em revestimentos de pavimentos para redução de emissões de poluentes e de consumo energético. Tese de Doutorado - Universidade de São Paulo. São Paulo, SP, Brasil, 2011.

NOVO ASFALTO. Como funciona o asfalto usinado a quente para aplicação a frio? Florianópolis, 2018. Disponível em: < https://novoasfalto.com/blog/comofunciona-o-asfalto-usinado-a-quente-para-aplicacao-a-frio/>Acesso: em 20 de maio de 2020.

NOVO ASFALTO. QUAL A DIFERENÇA ENTRE ASFALTO FRIO X PMF? Florianópolis, 2018. Disponível em: < https://novoasfalto.com/blog/asfaltofrio-xpmf/>Acesso: em 22 de outubro de 2020. 
SENÇO, Wlastermiler de. Manual de Técnicas de Pavimentação. vol. 1. 2. ed. São Paulo: Pini, 2001.

Enviado: Setembro, 2020.

Aprovado: Novembro, 2020. 